\title{
Sistem Pendukung Keputusan Untuk Menentukan Penerima BLSM Di Kabupaten Indramayu
}

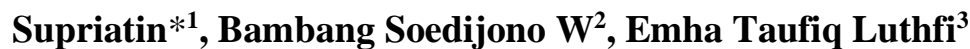 \\ 1,2,3 Magister Teknik Informatika STMIK AMIKOM Yogyakarta \\ E-mail: ${ }^{* 1}$ upie.supriatin@gmail.com, ${ }^{2}$ bambang.s@ amikom.ac.id, \\ ${ }^{3}$ emhataufiqluthfi@amikom.ac.id
}

\begin{abstract}
Abstrak
Bantuan Langsung Sementara Masyarakat (yang selanjutnya disebut BLSM) adalah kompensasi yang diberikan pemerintah kepada orang miskin guna mengurangi beban ekonomi yang semakin menekan kehidupan mereka, sebagai akibat naiknya harga BBM yang membawa dampak membubungnya harga kebutuhan pokok. Penelitian ini dilatarbelakangi oleh banyaknya kasus yang menyatakan bahwa penyaluran BLSM tidak tepat sasaran, ada BLSM yang diperuntukkan bagi masyarakat tidak mampu secara ekonomi, namun terkadang masih ada masyarakat kaya yang juga menerimanya khususnya di kabupaten Indramayu, hal tersebut menyulitkan pihak penyeleksi dalam mengadakan penyeleksian calon penerima dana BLSM ini untuk itu dibuat sistem pendukung keputusan dalam menentukan penerima BLSM di kabupaten Indramayu dengan menggunakan metode Analytic Hierarchy Process (AHP). Tujuan penelitian ini adalah Memberikan usulan untuk prioritas penerima BLSM agar tepat sasaran dan dapat membantu pemerintah kabupaten indramayu dalam pengambilan keputusan. Berdasarkan hasil analisis dengan menggunakan metode AHP, maka dapat dihasilkan suatu alternatif pengambilan keputusan dalam menentukan penerima BLSM yang efektif yang dapat menyaring $39 \%$ masyarakat yang seharusnya tidak mendapatkan BLSM.
\end{abstract}

Kata Kunci $-S P K, A H P, B L S M$

\begin{abstract}
Bantuan Langsung Sementara Masyarakat (BLSM) is the compensation given by the government to the poor in order to reduce the economic burden of an increasingly pressing their lives, as a result of rising fuel prices impact soaring prices of basic necessities. This research is motivated by the many cases which states that the distribution BLSM not on target, there BLSM not intended for economically disadvantaged communities, but sometimes there are people who also receive particularly rich in Kabupaten Indramayu, it is difficult for the selectors to selection of recipients of funds held BLSM made to the decision support system in determining the recipient BLSM in Kabupaten Indramayu using Analytic Hierarchy Processahp (AHP) method. The purpose of this study is to provide the proposed recipient BLSM priority for the right target and can help local governments indramayu in decision making. Based on the analysis by using the method of AHP, it can produce an alternative decision-making in determining effective BLSM receiver that can filter out $39 \%$ of the people who should not get BLSM.
\end{abstract}

Keywords-DSS, AHP, BLSM 


\section{PENDAHULUAN}

Mengikuti tindakan pemerintah menaikkan harga Bahan Bakar Minyak (BBM), Komisi VIII DPR menyetujui anggaran program Bantuan Langsung Sementara Masyarakat (BLSM) selama lima bulan, kurang lebih sebesar Rp.12 triliun untuk diberikan kepada orang miskin di Indonesia. BLSM adalah kompensasi yang diberikan pemerintah kepada orang miskin guna mengurangi beban ekonomi yang semakin menekan kehidupan mereka, sebagai akibat naiknya harga BBM yang membawa dampak membubungnya harga kebutuhan pokok[1].

Pada dasarnya tujuan pemberian BLSM adalah untuk menjaga tingkat konsumsi kelmpok miskin yang notabene jarang memiliki simpanan atau akses terhadap pinjaman saat terjadi guncangan ekonomi. Kondisi tersebut akan semakin diperparah dengan tingkat pendidikan yang rendah dan ketidaktrampilan tenaga kerja dari kelompok miskin. Oleh sebab itu, dengan tingkat konsumsi yang terjaga diharapkan mereka dapat meningkatkan kapasitasnya dalam mengelola resiko. Menurut peneliti bidang ekonomi kebijakan publik pada Pusat Pengkajian, Pengolahan Data dan Informasi (P3DI) Setjen DPR RI, Iwan Hermawan,di Indonesia BLSM merupakan salah satu program kompensasi selain dari penyaluran beras miskin (raskin), program keluarga harapan (PKH), dan bantuan siswa miskin (BSM). BLSM diberikan karena terjadi kenaikan harga Bahan Bakar Minyak (BBM khususnya premium dan solar) bersubsidi[2].

BLSM seharusnya diberikan kepada penerima yang layak dan pantas mendapatkannya. Sri Kusumastuti Rahayu, Ketua Pokja Pengendali Klaster I Program Bantuan Sosial TNP2K (Tim Nasional Percepatan Penanggulangan Kemiskinan) menjelaskan bahwa kriteria penerima BLSM disesuaikan pada masing-masing rumah tangga pada tiap daerah. Sehingga, antara setiap daerah yang satu dengan yang lain memiliki kriteria warga miskin yang berbeda-beda [3]. Sesuai dengan ketetapan Kriteria baku penerima dana BLSM oleh TNP2K adalah sebagai berikut: (1) luas lantai bangunan tempat tinggal kurang dari 8 meter persegi untuk masingmasing anggota keluarga, (2) jenis lantai bangunan tempat tinggal terbuat dari tanah, bambu, kayu berkualitas rendah, (3) jenis dinding bangunan tempat tinggal terbuat dari bambu, rumbia, kayu berkualitas rendah, (4) fasilitas jamban tidak ada, atau ada tetapi dimiliki secara bersamasama dengan keluarga lain, (5) sumber air untuk minum/memasak berasal dari sumur/mata air tak terlindung, air sungai, danau, atau air hujan, (6) sumber penerangan di rumah bukan listrik, (7) bahan bakar yang digunakan memasak berasal dari kayu bakar, arang, atau minyak tanah, (8) dalam seminggu tidak pernah mengonsumsi daging, susu, atau hanya sekali dalam seminggu, (9) dalam setahun paling tidak hanya mampu membeli pakaian baru satu stel, (10) makan dalam sehari hanya satu kali atau dua kali, (11) tidak mampu membayar anggota keluarga berobat ke puskesmas atau poliklinik, (12) pekerjaan utama kepala rumah tangga adalah petani dengan luas lahan setengah hektare, buruh tani, kuli bangunan, tukang batu, tukang becak, pemulung, atau pekerja informal lainnya dengan pendapatan maksimal Rp600 ribu per bulan, (13) pendidikan tertinggi yang ditamatkan kepala rumah tangga bersangkutan tidak lebih dari SD, (14) tidak memiliki harta senilai Rp500 ribu seperti tabungan, perhiasan emas, TV berwarna, ternak, sepeda motor (kredit/non-kredit), kapal motor, tanah, atau barang modal lainnya.

Penelitian Ayu Winda Istara, dkk (2013)[4] tentang Sistem Pendukung Keputusan Penentuan Pemberian Bantuan Raskin Menggunakan Metode Smarter. Membangun suatu sistem pendukung keputusan dalam menentukan pemberian RASKIN kepada masyarakat miskin dengan menggunakan metode SMARTER untuk menganalisa kriteria yang nantinya dapat menentukan penduduk mana yang layak menerima bantuan RASKIN. Penelitian tersebut memberikan sebuah permasalahan untuk dilakukannya sebuah penelitian mengenai sistem pendukung keputusan dalam menentukan bantuan.

Penelitian ini dilatarbelakangi oleh banyaknya kasus yang menyatakan bahwa penyaluran BLSM tidak tepat sasaran, Berdasarkan wawancara dengan Edi Rasdiana, S.Pd., M.Si. selaku sekretaris kecamatan Cikedung menyatakan bahwa ada BLSM yang 
diperuntukkan bagi masyarakat tidak mampu secara ekonomi, namun terkadang masih ada masyarakat kaya yang juga menerimanya. Untuk itu diperlukan suatu sistem yang bisa membantu proses seleksi penerima BLSM di kabupaten Indramayu khususnya. Sistem pendukung Keputusan (SPK) dapat memberikan pertimbangan prioritas penerima BLSM tertentu. SPK memperhitungkan segala kriteria yang mendukung pengambilan keputusan guna membantu, mempercepat dan mempermudah proses pengambilan keputusan. Sistem pendukung keputusan ini nantinya diterapkan ditingkat desa sehingga rumah tangga yang berhak menerima BLSM dapat ditentukan oleh aparat desa dan penerimanya sesuai dengan kriteria rumah tangga miskin pada daerah tersebut.

SPK dalam penelitian ini menggunakan metode Analitical Hierarchy Process (AHP) dengan berbasis web, hasil dari proses ini berupa tahapan ranking warga sebagai rekomendasi bagian pengambil keputusan untuk memilih warga yang cocok mendapatkan dana kompensasi BBM tersebut. Setiap calon warga mempunyai nilai yang berbeda-beda terhadap aspek yang diinginkan, penentuan calon warga mana yang diinginkan perlu sebuah alat bantu yang tepat yaitu dengan menggunakan komputer sebagai suatu sarana yang dapat membantu dan menggunakan metode analitycal hirarchi process. Metode ini dapat memberikan alternatif pilihan, pada dasarnya AHP merupakan suatu metode untuk memecahkan suatu masalah yang kompleks dan tidak terstruktur ke dalam suatu kelompok-kelompoknya, mengatur kelompok tersebut ke dalam suatu hirarki, memasukan nilai numerik sebagai pengganti persepsi manusia dalam melakukan perbandingan relatif yang akhirnya dengan dapat ditentukan elemen mana yang mempunyai prioritas tertinggi.

Banyak metode yang dapat digunakan dalam membangun sistem pendukung keputusan diantaranya adalah metode Analitical Hierarchy Process (AHP) dan Simple Additive Weighting (SAW). Metode AHP yang dikembangkan oleh Thomas L. Saaty dapat memecahkan masalah kompleks, dimana kriteria yang diambil cukup banyak, Struktur masalah yang belum jelas, ketidakpastian tersedianya data statistik yang akurat [5]. Metode SAW sering juga dikenal istilah metode penjumlahan terbobot. Konsep dasar metode SAW adalah mencari penjumlahan terbobot dari rating kinerja pada setiap alternatif pada semua atribut. Metode SAW membutuhkan proses normalisasi matriks keputusan $(\mathrm{X})$ ke suatu skala yang dapat diperbandingkan dengan semua rating alternatif yang ada. Hasil akhir diperoleh dari setiap proses perankingan yaitu penjumlahan dari perkalian matriks ternormalisasi $\mathrm{R}$ dengan vector bobot sehingga diperoleh nilai terbesar yang dipilih sebagai alternatif terbaik (Ai) sebagai solusi [6].

Letak perbedaan antara metode AHP dan SAW terdapat pada proses perhitungan nilai prioritas kriteria. Pada AHP penyelesaiannya dilakukan perbandingan berpasangan antara kriteria satu dengan kriteria yang lain serta subkriteria satu dan subkriteria yang dalam AHP. Hasil perbandingan berpasangan dibagi dengan jumlah elemen yang ada, sehingga diperoleh nilai prioritas dari setiap kriteria dan subkriteria yang dimaksud. Nilai prioritas dikalikan dengan nilai keadaan alternatif untuk mendapatkan nilai akhir, sedangkan pada SAW dilakukan penilaian kriteria terhadap keadaan alternatif yang kemudian hasil penilaian tersebut dinormalisasikan dan hasil normalisasi dikalikan dengan bobot kriteria atau prioritas kriteria yang ditentukan secara langsung oleh manajer [7]. Hasil akhir yang diberikan oleh kedua metode relatif sama akan tetapi metode AHP mampu memberikan informasi yang lebih akurat, karena pada metode AHP prosesnya dilakukan perbandingan berpasangan antara kriteria dan kriteria serta subkriteria dan subkriteria oleh karena itu dalam penelitian ini menggunakan metode AHP. 


\section{METODE PENELITIAN}

Merupakan acuan yang digunakan sebagai dasar dalam perancangan sistem. Langkahlangkah yang dilakukan dalam tahap ini adalah:

\subsection{Metode Penelitian}

Dalam penelitian ini digunakan metode action research. Pengertian dari metode action researchadalah kegiatan dan atau tindakan perbaikan sesuatu yang perencanaan, pelaksanaan, dan evaluasinya digarap secara sistematik sehingga validitas dan reliabilitasnya mencapai tingkatan riset [8]. Action research juga merupakan proses yang mencakup siklus aksi, yang mendasarkan pada refleksi, umpan balik (feedback), bukti (evidence), dan evaluasi atas aksi sebelumnya dan situasi sekarang.Penelitian tindakan bertujuan untuk memperoleh pengetahuan untuk situasi atau sasaran khusus dari pada pengetahuan yang secara ilmiah tergeneralisasi.untuk lebih jelasnya alur penelitian action research dijelaskan pada gambar dibawah ini [9]:

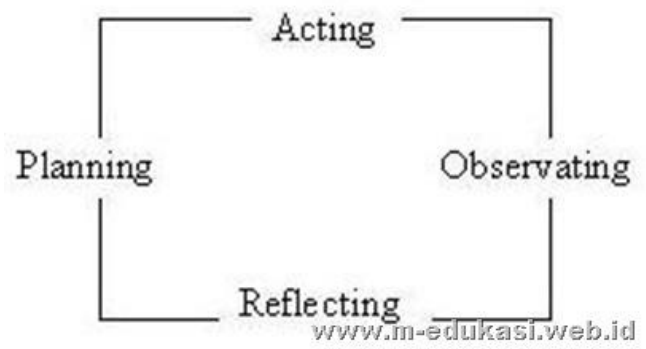

Gambar 1. Action Research Model Kurt Lewin

(Sumber: http://www.m-edukasi.web.id/2012/05/desain-ptk-model-kurt-lewin.html)

Gambar 1diatas merupakan beberapa tahapan dalam penelitian action research yang dilakukan. Penjelasan setiap proses adalah sebagai berikut:

1. Menyusun perencanaan (planning)

Pada tahap ini kegiatan yang harus dilakukan adalah mempersiapkan fasilitas dari sarana pendukung yang diperlukan dalam penelitian, mempersiapkan instrument untuk merekam dan menganalisis data mengenai proses dan hasil tindakan.

2. Melaksanakan tindakan (acting).

Pada tahap ini peneliti melakukan tindakan yang telah dirumuskan, dalam situasi yang actual, yang meliputi kegiatan awal, inti dan penutup.

3. Melaksanakan pengamatan (observing)

Tahap penelitian disini adalah tahap pengumpulan data. Tahap ini dimaksudkan untuk mengumpulkan data pendukung yang dibutuhkan dalam proses penelitian yaitu dengan cara observasi dan wawancara.

4. Melakukan refleksi (reflecting)

Pada tahap ini adalah mencatat hasil observasi, mengevaluasi hasil observasi, menganalisis hasil pembelajaran, mencatat kekurangan-kekurangan untuk dijadikan bahan penyusunan rancangan sistem pendukung keputusan agar tujuan tercapai.

\subsection{Metode Pengumpulan Data}

Metode pengumpulan data berdasarkan jenis datanya, data yang dikumpulkan dalam penelitian ini adalah sebagai berikut [10]:

1. Data Primer

Data primer adalah data yang diambil langsung dari obyek penelitian atau merupakan data yang berasal dari sumber asli atau pertama. Teknik pengumpulan data primer dilakukan 
melalui teknik observasi dengan cara mengumpulkan informasi informasi langsung ke lokasi penelitian untuk mengamati bagaimana penentuan dan pembagian BLSM yang dilakukan oleh pihak pemerintah daerah kabupaten Indramayu dengan cara pengamatan dan pencatatan dengan peninjauan langsung dan wawancara dengan melakukan wawancara terstruktur dengan menyediakan daftar pertanyaan untuk mewawancarai petugas Tenaga Kesejahteraan Sosial Kecamatan (TKSK) mengenai bagaimana pembagian BLSM yang diterapkan selama ini. Data yang dihasilkan yaitu informasi berupa opini dari pihak tersebut.

2. Data Sekunder

Data sekunder adalah data yang tidak didapatkan secara langsung dari objek penelitian, melainkan data yang berasal dari sumber yang telah dikumpulkan oleh pihak lain. Teknik pengumpulan data sekunder dilakukan dengan cara studi dokumentasi dan studi literatur.

\subsection{Metode Analisis Data}

Metode yang digunakan dalam penelitian ini adalah metode deskriptif analisis dengan menggunakan pendekatan kuantitatif. Tujuan dari metode deskriptif analisis dengan pendekatan kuantitatif ini yaitu membuat suatu uraian yang sistematis mengenai fakta-fakta dan sifat-sifat dari objek yang diteliti kemudian menggabungkan hubungan antar variabel yang terlibat didalamnya. Penelitian ini juga menekankan analisisnya pada data-data numerik (angka) yang diolah dengan menggunakan metode statistika.

\subsection{Analytic Hierarchy Processahp (AHP)}

Urutan langkah-langkah pemecahan masalah dalam penelitian ini adalah sebagai berikut:

1. Menentukan jenis-jenis kriteria calon penerima BLSM.

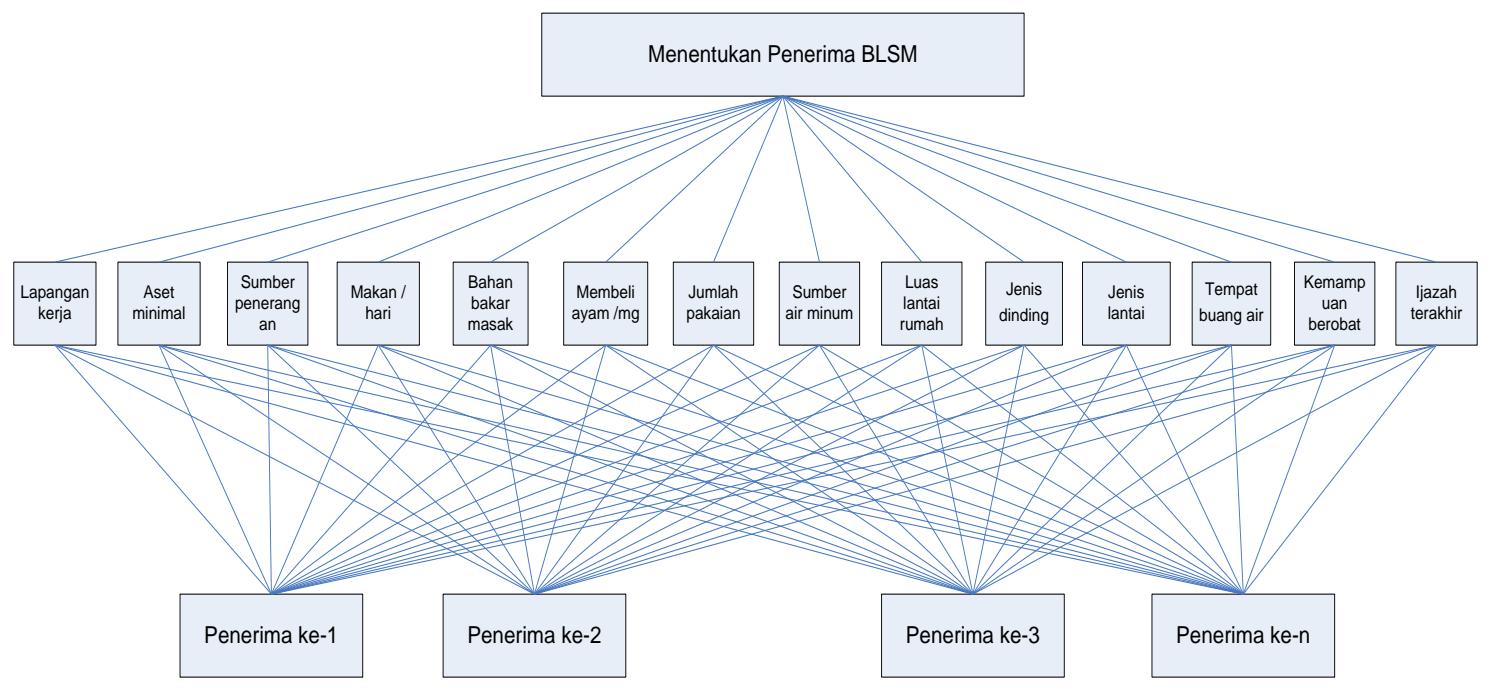

Gambar 2. Hirearki menentukan penerima BLSM

Kriteria-kriteria yang dibutuhkan calon penerima BLSM adalah lapangan pekerjaan, aset minimal, sumber penerangan, jumlah pakaian baru /tahun, bahan bakar masak, membeli ayam /minggu, makan per hari, sumber air minum, luas lantai rumah, jenis dinding, jenis lantai, tempat buang air, kemampuan berobat, ijazah terakhir.

2. Menyusun kriteria-kriteria calon penerima BLSM dalam matriks berpasangan.

3. Menjumlah setiap kolom pada matriks berpasangan

4. Menentukan nilai elemen kolom kriteria dengan rumus tiap-tiap sel pada table perbandingan berpasangan dibagi dengan masing-masing jumlah kolom pada langkah 3 
5. Menentukan prioritas kriteria pada masing-masing dengan rumus jumlah baris dibagi dengan banyak kriteria.

6. Menghitung maksimum, CI dan CR. $\lambda$

\section{HASIL DAN PEMBAHASAN}

Pada Sistem pendukung keputusan dalam menentukan penerima BLSM dengan menggunakan metode AHP memiliki input, proses dan output. Input yang dibutuhkan dalam sistem ini adalah data kriteria, sub kriteria dan data nilai perbandingan matriks antar kriteria dan subkriteria, Proses yang dilakukan pada sistem ini adalah proses perhitungan untuk mendapatkan bobot kriteria dan subkriteria, sedangkan output adalah hasil perankingan data penduduk miskin yang direkomendasikan oleh sistem utuk calon penerima dana BLSM dan dalam bentuk grafik. Untuk mengetahui pola atau populasi penduduk miskin bisa menggunakan SIG (Sistem Informasi Geografis) tetapi pada penelitian ini belum menggunakan SIG.

\subsection{Analisa dan Rancangan Sistem}

\subsubsection{Analisa Data}

Dalam pembuatan Sistem pendukung keputusan untuk menetukan penerima BLSM di Indramayu dibutuhkan jenis data internal dan data privat.

1. Data Internal

Data internal adalah data yang sudah ada dalam organisasi. Dalam penelitian ini data internalnya adalah data penduduk miskin yang ada di kabupeten Indramayu.

2. Data Privat

Data privat merupakan data pendapat dari user.Dalam penelitian ini data privatnya adalah data kriteria yang sudah ditetapkan yang akan digunakan dalam menyelesaikan masalah.

\subsubsection{Analisis Hasil Penelitian}

Berdasarkan rumus yang telah dijelaskan sebelumnya, pada subbab ini akan dibahas tentang masukan data yang sebenarnya, proses perhitungan dan keluaran yang diharapkan pada penelitian ini. Masukan sistem ini adalah nilai matriks kriteria dan nilai matriks sub kriteria.

1. Menyusun Kriteria calon penerima BLSM.

Menyusun kriteria-kriteria calon penerima BLSM pada matriks berpasangan. Misalkan data yang dimasukkan dapat dilihat pada tabel 1 .

2. Memasukkan nilai Perbandingan kriteria Penerima BLSM.

Memasukkan nilai atau angka yang menggambarkan bobot nilai pada setiap sel pada tabel untuk dijadikan tolak ukur pembobotan nilai. Dapat dilihat pada tabel 1. 
Tabel 1. Masukan Nilai Perbandingan Kriteria Penerima BLSM

\begin{tabular}{|c|c|c|c|c|c|c|c|c|c|c|c|c|c|c|}
\hline Kriteria & $\begin{array}{l}\text { Lapangan } \\
\text { Pekerjaan }\end{array}$ & $\begin{array}{l}\begin{array}{l}\text { Aset } \\
\text { minimal }\end{array} \\
\end{array}$ & $\begin{array}{l}\text { Sumber } \\
\text { penerangan }\end{array}$ & $\begin{array}{l}\text { makan } \\
\text { per hari }\end{array}$ & $\begin{array}{l}\text { Bahan } \\
\text { bakar } \\
\text { masak }\end{array}$ & $\begin{array}{l}\text { membeli } \\
\text { ayam } \\
\text { /minggu }\end{array}$ & $\begin{array}{l}\text { Jumlah } \\
\text { paksian }\end{array}$ & $\begin{array}{l}\text { Sumber } \\
\text { air } \\
\text { minum } \\
\end{array}$ & $\begin{array}{l}\text { luas } \\
\text { lantai } \\
\text { rumah }\end{array}$ & $\begin{array}{l}\text { jenis } \\
\text { dinding }\end{array}$ & $\begin{array}{l}\text { jenis } \\
\text { lantai } \\
\end{array}$ & $\begin{array}{l}\text { tempat } \\
\text { buang } \\
\text { air }\end{array}$ & $\begin{array}{l}\text { kemampuan } \\
\text { berobat }\end{array}$ & $\begin{array}{l}\text { Ijazah } \\
\text { terakhir }\end{array}$ \\
\hline Lapangan Pekerjagn & 1 & 5 & 5 & 5 & 7 & 7 & 3 & 5 & 3 & 3 & 3 & 3 & 3 & 5 \\
\hline Asetminimal & 0,2000 & 1 & 5 & 5 & 5 & 3 & 2 & 3 & 3 & 2 & 5 & 5 & 3 & 3 \\
\hline Sumber penerangan & 0,2000 & 0,2000 & 1 & 3 & 5 & 3 & 3 & 3 & 5 & 5 & 5 & 5 & 5 & 5 \\
\hline makan per hari & 0,2000 & 0,2000 & 0,3333 & 1 & 5 & 7 & 3 & 5 & 5 & 3 & 2 & 2 & 5 & 5 \\
\hline Bahan bakar masalk & 0,1429 & 0,2000 & 0,2000 & 0,2000 & 1 & 5 & 5 & 3 & 3 & 3 & 3 & 5 & 5 & 5 \\
\hline membeli ayam/minggu & 0,1429 & 0,3333 & 0,3333 & 0,1429 & 0,2000 & 1 & 3 & 3 & 2 & 2 & 2 & 3 & 3 & 3 \\
\hline Jumlah Pakaian & 0,3333 & 0,5000 & 0,3333 & 0,3333 & 0,2000 & 0,3333 & 1 & 3 & 3 & 5 & 2 & 2 & 3 & 3 \\
\hline Sumber air mirum & 0,2000 & 0,3333 & 0,3333 & 0,2000 & 0,3333 & 0,3333 & 0,3333 & 1 & 5 & 5 & 5 & 5 & 5 & 5 \\
\hline luas lantai rumah & 0,3333 & 0,3333 & 0,2000 & 0,2000 & 0,3333 & 0,5000 & 0,3333 & 0,2000 & 1 & 3 & 5 & 3 & 3 & 3 \\
\hline jenis dinding & 0,3333 & 0,5000 & 0,2000 & 0,3333 & 0,3333 & 0,5000 & 0,2000 & 0,2000 & 0,3333 & 1 & 3 & 5 & 2 & 2 \\
\hline jenis lantai & 0,3333 & 0,2000 & 0,2000 & 0,5000 & 0,3333 & 0,5000 & 0,5000 & 0,2000 & 0,2000 & 0,3333 & 1 & 5 & 3 & 3 \\
\hline tempat buang air & 0,3333 & 0,2000 & 0,2000 & 0,5000 & 0,2000 & 0,3333 & 0,5000 & 0,2000 & 0,3333 & 0,2000 & 0,2000 & 1 & 3 & 5 \\
\hline kemampuan berobat & 0,3333 & 0,3333 & 0,2000 & 0,2000 & 0,2000 & 0,3333 & 0,3333 & 0,2000 & 0,3333 & 0,5000 & 0,3333 & 0,3333 & 1 & 5 \\
\hline Ijazah terakhir & 0,2000 & 0,3333 & 0,2000 & 0,2000 & 0,2000 & 0,3333 & 0,3333 & 0,2000 & 0,3333 & 0,5000 & 0,333333 & 0,2000 & 0,2000 & 1 \\
\hline Jumlah & 4.2857 & 9.6667 & 13,7333 & 16.8095 & 25.3333 & 29.1667 & 22.5333 & 27.2000 & 31.5333 & 33,5333 & 36,8667 & 44,5333 & 44.2 & 53 \\
\hline
\end{tabular}

Segitiga atas merupakan inputan nilai yang menggambarkan bobot nilai kriteria, sedangkan segitiga bawah merupakan kebalikan dari segitiga atas dengan rumus

$a[j, i]=\frac{1}{a[i, j]}$ Untuk $\mathrm{i} \neq \mathrm{j}$

kemudian setiap kolom dijumlahkan.

3. Nilai Pembagian Jumlah Kolom Kriteria Penerima BLSM

Setelah dimasukkan data pada Tabel 1 di atas, maka tahap selanjutnya adalah membagi nilai masing-masing sel pada tabel $1 \mathrm{di}$ atas dengan jumlah masing-masing kolomnya. Untuk lebih jelasnya dapat dilihat pada Tabel 2 yaitu hasil perhitungan yang diperoleh dengan menggunakan rumus berikut ini:

Tabel 2. Nilai Pembagian Jumlah Kolom Kriteria Penerima BLSM

\begin{tabular}{|c|c|c|c|c|c|c|c|c|c|c|c|c|c|c|c|}
\hline Kriteria & $\begin{array}{l}\text { Lapangan } \\
\text { Pekerjaan }\end{array}$ & $\begin{array}{l}\text { Aset } \\
\text { minimal }\end{array}$ & $\begin{array}{l}\text { Sumber } \\
\text { penerangan }\end{array}$ & $\begin{array}{l}\text { makan } \\
\text { per hari }\end{array}$ & $\begin{array}{l}\text { Bahan } \\
\text { bakas } \\
\text { massak }\end{array}$ & $\begin{array}{l}\text { membali } \\
\text { ayam } \\
/ \operatorname{ming} g \mathrm{gu}\end{array}$ & $\begin{array}{l}\text { Jumlah } \\
\text { pakaian }\end{array}$ & $\begin{array}{l}\text { Sumber } \\
\text { air } \\
\text { minum } \\
\end{array}$ & $\begin{array}{l}\text { luas } \\
\text { lantai } \\
\text { rumah }\end{array}$ & $\begin{array}{l}\text { jenis } \\
\text { dinding }\end{array}$ & $\begin{array}{l}\text { jenis } \\
\text { lantai }\end{array}$ & $\begin{array}{l}\text { tempat } \\
\text { buang air }\end{array}$ & $\begin{array}{l}\text { kemampuan } \\
\text { berobat }\end{array}$ & \begin{tabular}{|l}
$\begin{array}{l}\text { Ijazah } \\
\text { terakhir }\end{array}$ \\
\end{tabular} & Jumlah \\
\hline Lappangan Pekerjasn & 0,23333 & 0,5172 & 0,3641 & 0,2975 & 0,2763 & 0,2400 & 0,1331 & 0,1838 & 0,0951 & 0,0895 & 0,0814 & 0,0674 & 0,0679 & 0,0943 & 2,7409 \\
\hline Asetminimal & 0,04667 & 0,1034 & 0,3641 & 0,2975 & 0,1974 & 0,1029 & 0,0888 & 0,1103 & 0,0951 & 0,0596 & 0,1356 & 0,1123 & 0,0679 & 0,0566 & 1,8381 \\
\hline Sumber penermgngan & 0,04667 & 0,0207 & 0,0728 & 0,1785 & 0,1974 & 0,1029 & 0,1331 & 0,1103 & 0,1586 & 0,1491 & 0,1356 & 0,1123 & 0,1131 & 0,0943 & 1,6253 \\
\hline makan per hari & 0,04667 & 0,0207 & 0,0243 & 0,0595 & 0,1974 & 0,2400 & 0,1331 & 0,1838 & 0,1586 & 0,0895 & 0,0542 & 0,0449 & 0,1131 & 0,0943 & 1,4601 \\
\hline Bahan bakar masak & 0,03333 & 0,0207 & 0,0146 & 0,0119 & 0,0395 & 0,1714 & 0,2219 & 0,1103 & 0,0951 & 0,0895 & 0,0814 & 0,1123 & 0,1131 & 0,0943 & 1,2093 \\
\hline membeli ayamperminggu & 0,03333 & 0,0345 & 0,0243 & 0,0085 & 0,0079 & 0,0343 & 0,1331 & 0,1103 & 0,0634 & 0,0596 & 0,0542 & 0,0674 & 0,0679 & 0,0566 & 0,7554 \\
\hline Jumlah Pakaian & 0,07778 & 0,0517 & 0,0243 & 0,0198 & 0,0079 & 0,0114 & 0,0444 & 0,1103 & 0,0951 & 0,1491 & 0,0542 & 0,0449 & 0,0679 & 0,0566 & 0,8155 \\
\hline Sumber air minum & 0,04667 & 0,0345 & 0,0243 & 0,0119 & 0,0132 & 0,0114 & 0,0148 & 0,0368 & 0,1586 & 0,1491 & 0,1356 & 0,1123 & 0,1131 & 0,0943 & 0,9565 \\
\hline luas lantai rumah & 0,07778 & 0,0345 & 0,0146 & 0,0119 & 0,0132 & 0,0171 & 0,0148 & 0,0074 & 0,0317 & 0,0895 & 0,1356 & 0,0674 & 0,0679 & 0,0566 & 0,6398 \\
\hline jenis dinding & 0,07778 & 0,0517 & 0,0146 & 0,0198 & 0,0132 & 0,0171 & 0,0089 & 0,0074 & 0,0106 & 0,0298 & 0,0814 & 0,1123 & 0,0452 & 0,0377 & 0,5275 \\
\hline jenis lantai & 0,07778 & 0,0207 & 0,0146 & 0,0297 & 0,0132 & 0,0171 & 0,0222 & 0,0074 & 0,0063 & 0,0099 & 0,0271 & 0,1123 & 0,0679 & 0,0566 & 0,4828 \\
\hline tempat buang air & 0,07778 & 0,0207 & 0,0146 & 0,0297 & 0,0079 & 0,0114 & 0,0222 & 0,0074 & 0,0106 & 0,0060 & 0,0054 & 0,0225 & 0,0679 & 0,0943 & 0,3983 \\
\hline kemampuan berobat & 0,07778 & 0,0345 & 0,0146 & 0,0119 & 0,0079 & 0,0114 & 0,0148 & 0,0074 & 0,0106 & 0,0149 & 0,0090 & 0,0075 & 0,0226 & 0,0943 & 0,3392 \\
\hline Ijazzh terakhir & 0,04667 & 0,0345 & 0,0146 & 0,0119 & 0,0079 & 0,0114 & 0,0148 & 0,0074 & 0,0106 & 0,0149 & 0,0090 & 0,0045 & 0,0045 & 0,0189 & 0.2115 \\
\hline
\end{tabular}

Rumus yang digunakan untuk menghitung tabel 2 diatas adalah

Hkkrit $=($ Xkrit1 ...Xkrit14) $/$ Kkrit

Keterangan :

Xkrit1 $=$ Setiap sel kolom kriteria1.

Xkrit14 = Setiap sel kolom kriteria14

Hkkrit $=$ Hasil bagi setiap sel kolom kriteria1 dengan jumlah kolom kriteria 1.

Setelah setiap sel dibagi kemudian setiap baris dijumlahkan.

4. Nilai Prioritas Kriteria

Menghitung prioritas kriteria dapat dilihat pada Tabel 3 hasil perhitungan yang diperoleh dengan menggunakan rumus jumlah kolom kriteria penerima BLSM dibagi dengan banyak kriteria. Dapat dilihat dari tabel 3: 
Citec Journal, Vol. 1, No. 4, Agustus 2014 - Oktober 2014

Tabel 3. Nilai Prioritas Kriteria

\begin{tabular}{|l|c|}
\hline Kriteria & $\begin{array}{c}\text { Prioritas } \\
\text { Kriteria }\end{array}$ \\
\hline Lapangan Pekerjaan & 0,1958 \\
\hline Aset minimal & 0,1313 \\
\hline Sumber penerangan & 0,1161 \\
\hline makan per hari & 0,1043 \\
\hline Bahan bakar masak & 0,0864 \\
\hline membeli ayam per minggu & 0,0540 \\
\hline Jumlah Pakaian & 0,0582 \\
\hline Sumber air minum & 0,0683 \\
\hline luas lantai rumah & 0,0457 \\
\hline jenis dinding & 0,0377 \\
\hline jenis lantai & 0,0345 \\
\hline tempat buang air & 0,0284 \\
\hline kemampuan berobat & 0,0242 \\
\hline Ijazah terakhir & 0,0151 \\
\hline
\end{tabular}

Menghitung prioritas kriteria dengan menggunakan rumus

$\mathrm{B}_{\text {krit }}=\sum_{\mathrm{j}=1}^{\mathrm{n}} \mathrm{a}[1, \mathrm{j}]$

Keterangan:

$\mathrm{Blp}=$ Jumlah baris lapangan pekerjaan

$\mathrm{J}=$ kolom

5. Perkalian nilai masukan Matriks kriteria dengan Nilai Prioritas Kriteria Langkah selanjutnya adalah nilai matriks pada kolom masukan pada tabel 1 dikalikan dengan prioritas kriteria pada tabel 3 Hasilnya dapat dilihat pada tabel 4:

Tabel 4. Nilai Masukan Matriks kriteria Dikali Nilai Prioritas Kriteria

\begin{tabular}{|c|c|c|c|c|c|c|c|c|c|c|c|c|c|c|c|}
\hline Kriteria & $\begin{array}{l}\text { Lapangan } \\
\text { Pekerjaan }\end{array}$ & $\begin{array}{l}\text { Aset } \\
\text { minimal }\end{array}$ & $\begin{array}{l}\text { Sumber } \\
\text { penerangan }\end{array}$ & $\begin{array}{l}\text { makan } \\
\text { per } \\
\text { hari }\end{array}$ & $\begin{array}{l}\text { Bahan } \\
\text { bakar } \\
\text { masak }\end{array}$ & $\begin{array}{l}\text { membeli } \\
\text { aygm } \\
\text { /minggug }\end{array}$ & $\begin{array}{l}\text { Jumlah } \\
\text { paksian }\end{array}$ & \begin{tabular}{|l|} 
Sumber \\
air \\
minum \\
\end{tabular} & $\begin{array}{l}\text { luas } \\
\text { lantai } \\
\text { rumah }\end{array}$ & $\begin{array}{l}\text { jenis } \\
\text { dinding }\end{array}$ & $\begin{array}{l}\text { jenis } \\
\text { lantai }\end{array}$ & $\begin{array}{l}\text { tempat } \\
\text { buangair }\end{array}$ & $\begin{array}{l}\text { kemanmpuan } \\
\text { berobat }\end{array}$ & $\begin{array}{l}\text { Ijazah } \\
\text { terakhir }\end{array}$ & Jumlah \\
\hline Lapangan Pekerjasn & 0,1958 & 0,6565 & 0,5805 & 0,5215 & 0,6046 & 0,3777 & 0,1747 & 0,3416 & 0,1371 & 0,1130 & 0,1035 & 0,0853 & 0,0727 & 0,0755 & 4,0400 \\
\hline Asetminimal & 0,0392 & 0,1313 & 0,5805 & 0,5215 & 0,4319 & 0,1619 & 0,1165 & 0,2050 & 0,1371 & 0,0754 & 0,1724 & 0,1422 & 0,0727 & 0,0453 & 2,8327 \\
\hline Sumber penerangan & 0,0392 & 0,0263 & 0,1161 & 0,3129 & 0,4319 & 0,1619 & 0,1747 & 0,2050 & 0,2285 & 0,1884 & 0,1724 & 0,1422 & 0,1211 & 0,0755 & 2,3960 \\
\hline makan per hari & 0,0392 & 0,0263 & 0,0387 & 0,1043 & 0,4319 & 0,3777 & 0,1747 & 0,3416 & 0,2285 & 0,1130 & 0,0690 & 0,0569 & 0,1211 & 0,0755 & 2,1984 \\
\hline Bahan bakar masak & 0,0280 & 0,0263 & 0,0232 & 0,0209 & 0,0864 & 0,2698 & 0,2912 & 0,2050 & 0,1371 & 0,1130 & 0,1035 & 0,1422 & 0,1211 & 0,0755 & 1,6431 \\
\hline membeli ayamperminggu & 0,0280 & 0,0438 & 0,0387 & 0,0149 & 0,0173 & 0,0540 & 0,1747 & 0,2050 & 0,0914 & 0,0754 & 0,0690 & 0,0853 & 0,0727 & 0,0453 & 1,0153 \\
\hline Jumlah Pakaian & 0,0653 & 0,0656 & 0,0387 & 0,0348 & 0,0173 & 0,0180 & 0,0582 & 0,2050 & 0,1371 & 0,1884 & 0,0690 & 0,0569 & 0,0727 & 0,0453 & 1,0722 \\
\hline Sumber air minum & 0,0392 & 0,0438 & 0,0028 & 0,0209 & 0,0288 & 0,0180 & 0,0194 & 0,0683 & 0,2285 & 0,1884 & 0,1724 & 0,1422 & 0,1211 & 0,0755 & 1,1693 \\
\hline luas lantai rumah & 0,0653 & 0,0438 & 0,0232 & 0,0209 & 0,0288 & 0,0270 & 0,0194 & 0,0137 & 0,0457 & 0,1130 & 0,1724 & 0,0853 & 0,0727 & 0,0453 & 0,7764 \\
\hline jenis dinding & 0,0653 & 0,0656 & 0,0232 & 0,0348 & 0,0288 & 0,0270 & 0,0116 & 0,0137 & 0,0152 & 0,0377 & 0,1035 & 0,1422 & 0,0485 & 0,0302 & 0,6472 \\
\hline jenis lantai & 0,0653 & 0,0263 & 0,0232 & 0,0521 & 0,0288 & 0,0270 & 0,0291 & 0,0137 & 0,0091 & 0,0126 & 0,0345 & 0,1422 & 0,0727 & 0,0453 & 0,5819 \\
\hline tempat buang air & 0,0653 & 0,0263 & 0,0232 & 0,0521 & 0,0173 & 0,0180 & 0,0291 & 0,0137 & 0,0152 & 0,0075 & 0,0069 & 0,0284 & 0,0727 & 0,0755 & 0,4513 \\
\hline kemampuan berobat & 0,0653 & 0,0438 & 0,0232 & 0,0209 & 0,0173 & 0,0180 & 0,0194 & 0,0137 & 0,0152 & 0,0188 & 0,0115 & 0,0095 & 0,0242 & 0,0755 & 0,3762 \\
\hline Ijazah terakhir & 0,0392 & 0,0438 & 0,0232 & 0,0209 & 0,0173 & 0,0180 & 0,0194 & 0,0137 & 0,0152 & 0,0188 & 0,0115 & 0,0057 & 0,0048 & 0,0151 & 0.2665 \\
\hline
\end{tabular}


6. Jumlah baris yang dihasilkan pada tabel 4 di atas dibagi dengan nilai prioritas masingmasing kriteria pada tabel 3 Hasilnya dapat dilihat pada tabel 5

Tabel 5. Hasil Bagi Nilai Jumlah Baris Tabel 4. dengan Nilai Prioritas Kriteria

\begin{tabular}{l|c|}
\hline Kriteria & lamda $(\boldsymbol{\lambda})$ \\
\hline Lapangan Pekerjaan & 20,6352 \\
\hline Aset minimal & 21,5757 \\
\hline Sumber penerangan & 20,6387 \\
\hline makan per hari & 21,0790 \\
\hline Bahan bakar masak & 19,0227 \\
\hline membeli ayam per minggu & 18,8184 \\
\hline Jumlah Pakaian & 18,4069 \\
\hline Sumber air minum & 17,1150 \\
\hline luas lantai rumah & 16,9896 \\
\hline jenis dinding & 17,1794 \\
\hline jenis lantai & 16,8732 \\
\hline tempat buang air & 15,8625 \\
\hline kemampuan berobat & 15,5308 \\
\hline jjazah terakhir & 17,6447 \\
\hline Total & $\mathbf{2 5 7 , 3 7 1 9}$ \\
\hline$\lambda$ max & $\mathbf{1 8 , 3 8 3 7}$ \\
\hline
\end{tabular}

Nilai total pada tabel di atas diperoleh dari penjumlahan semua nilai hasil bagi kriteria, sedangkan nilai $\lambda$ Max diperoleh dari nilai Total dibagi banyaknya kriteria yang ada yakni 14.

7. Mencari nilai Consistency Index (CI) dan nilai Consistency Ratio (CR)

$$
\begin{aligned}
\mathrm{CI} & =(\lambda \text { max-n }) /(\mathrm{n}-1) \\
& =(18,3837-14) /(14-1) \\
& =(4,3837) / 13 \\
& =0,3372 \\
& =\mathrm{CI} / \mathrm{RI} \\
& =0,3372 / 1,57 \\
& =0,0214(\mathrm{CR}<0,1, \text { nilai ACCEPTABLE })
\end{aligned}
$$

\subsubsection{Penentuan Pembobotan untuk Menentukan Penerima BLSM}

1. Penentuan Pembobotan menentukan bobot pada tiap kriteria, nilai bobot ini berkisar antara 0 - 1. Dan total bobot untuk setiap kolom adalah 1. Cara menghitung bobot adalah angka pada setiap kotak dibagi dengan penjumlahan semua angka dalam kolom yang sama. (Merujuk pada tabel 3.11).

Contoh bobot dari (Lapangan pekerjaan, Lapangan pekerjaan) $=1 /$ $(1+0,2+0,2+0,2+0,14+0,14+0,33+0,2+0,33+0,33+0,33+0,33+0,33+0,2)$ $=0,2333$

(Aset minimal, Aset minimal $)=0,2 /$

$(1+0,2+0,2+0,2+0,14+0,14+0,33+0,2+0,33+0,33+0,33+0,33+0,33+0,2)=0,0466$

Dengan perhitungan yang sama bobot maka prioritas kriteria dapat diperoleh (Tabel 3.12).

2. Menentukan Nilai Bobot dan Prioritas

Mencari nilai bobot untuk masing-masing kriteria. Dengan melakukan penjumlahan setiap nilai bobot prioritas pada setiap baris tabel dibagi dengan jumlah kriteria. Sehingga 
Citec Journal, Vol. 1, No. 4, Agustus 2014 - Oktober 2014

diperoleh bobot masing-masing kriteria. (Merujut pada tabel 3.12). Sehingga diperoleh bobot masing-masing :

Lapangan pekerjaan $=(0,233+0,517+0,364+0,297+0,276+0,240+0,133+0,183+$ $0,095+0,089+0,081+0,067+0,067+0,094) / 14=0,1958(19,58 \%)$

Aset Minimal $=(0,046+0,103+0,364+0,297+0,197+0,102+0,088+0,110+0,095+$ $0,059+0,135+0,112+0,067+0,056) / 14=0,1313(13,13 \%)$

Dengan perhitungan yang sama

Sumber penerangan $=0,1161(11,61 \%)$

Makan Perhari $=0,1043(10,43 \%)$

Tabel 6. Pembobotan

\begin{tabular}{|l|c|c|}
\hline Kriteria & $\begin{array}{c}\text { Prioritas } \\
\text { Kriteria }\end{array}$ & $\%$ \\
\hline Lapangan Pekerjaan & 0,1958 & 19,58 \\
\hline Aset minimal & 0,1313 & 13,13 \\
\hline Sumber penerangan & 0,1161 & 11,61 \\
\hline makan per hari & 0,1043 & 10,43 \\
\hline Bahan bakar masak & 0,0864 & 8,64 \\
\hline membeli ayam per minggu & 0,0540 & 5,40 \\
\hline Jumlah Pakaian & 0,0582 & 5,82 \\
\hline Sumber air minum & 0,0683 & 6,83 \\
\hline luas lantai rumah & 0,0457 & 4,57 \\
\hline jenis dinding & 0,0377 & 3,77 \\
\hline jenis lantai & 0,0345 & 3,45 \\
\hline tempat buang air & 0,0284 & 2,84 \\
\hline kemampuan berobat & 0,0242 & 2,42 \\
\hline Ijazah terakhir & 0,0151 & 1,51 \\
\hline Jumlah & $\mathbf{1}$ & $\mathbf{1 0 0}$ \\
\hline
\end{tabular}

Sehingga jumlah total bobot semua kriteria $=1(100 \%)$ sesuai dengan kaidah pembobotan dimana jumlah total bobot harus bernilai 100. T abel 6menunjukkan bahwa dengan penggunaan metode AHP, maka semua alternatif pemecahan masalah (untuk menentukan penerima BLSM) dapat ditentukan prioritasnya dengan baik. Dari analisi tersebut diperoleh bahwa kriteria Lapangan pekerjaan $(19,58 \%)$ menempati prioritas pertama dan kriteria yang merupkan prioritas terakhir adalah Ijazah terakhir $(1,51 \%)$.

\subsection{Implementasi}

\subsubsection{Pengujian}

Sesuai dengan rancangan fisik sebagai dokumentasi aplikasi, maka program yang dibuat haruslah sesuai dengan dokumentasi yang telah dibuat. Dalam penerapan kode-kode program yang membangun Sistem Pendukung Keputusan berbasis website ini juga harus diuji agar terhindar dari kesalahan program secara menyeluruh.

1. Uji Black Box

Uji coba black box yaitu pengujian spesifikasi suatu fungsi atau modul apakah berjalan dengan yang diharapkan atau tidak. Pengujian ini berfokus pada persyaratan fungsional perangkat lunak. Contohnya pada halaman ganti password, dapat dilihat pada gambar 3: 


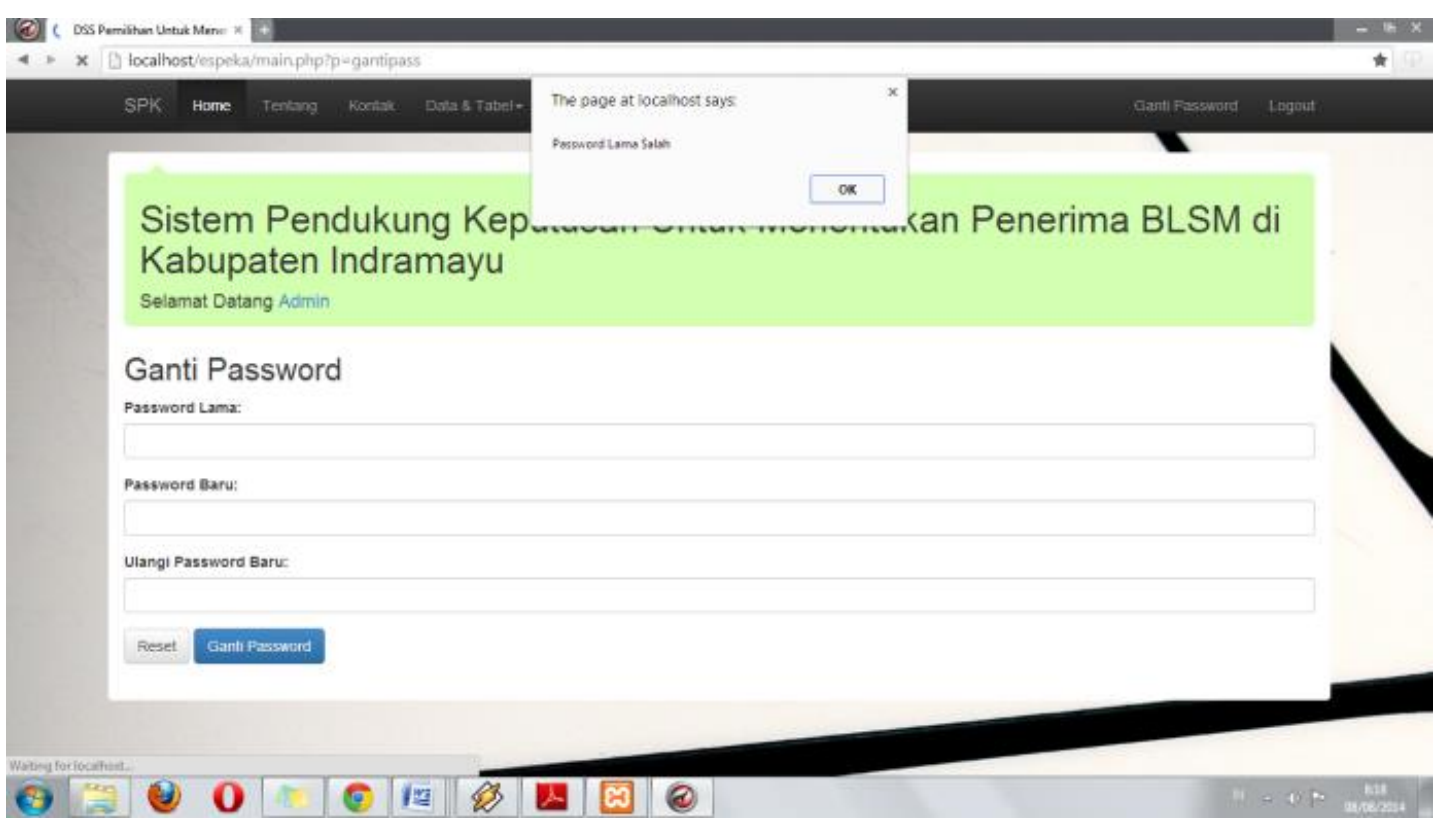

Gambar 3. Uji Black Box

Halaman password ini digunakan untuk mengganti password yang akan digunakan untuk masuk ke dalam sistem. Apabila password lama yang dimasukkan salah maka akan muncul peringatan.

2. User Acceptance Test

User Acceptance Testing (UAT)adalah proses untuk mendapatkan konfirmasi bahwa sebuah sistem memenuhi yang disepakati persyaratan dan mengetes apakah semua fungsi dan fitur berjalan dengan baik. Caranya, user mencoba software dalam hal ini adalah sistem pendukung keputusan untuk semua kondisi data dan mencocokkannya dengan hasil yang diharapkan. Apabila hasil semua tes sesuai dengan keluaran yang diharapkan, maka tes tersebut dinyatakan berhasil. Apabila ada beberapa fitur yang tidak memberikan keluaran yang diharapkan, maka aplikasi diperbaiki untuk disesuaikan dengan keluaran yang diharapkan atau ditolak.Penelitian inimelakukan tes UAT dengan cara membuat kuesioner mengenai kepuasan user, kuesioner yang dibuat yaitu menyajikan pertanyaan-pertanyaan yang berhubungan dengan aplikasi. Dari hasil kuesioner tersebut dapat diketahui penilaian calon pengguna terhadap perangkat lunak yang telah dibangun.

3. Pengujian Sistem

Pengujian sistem yang dilakukan untuk menguji apakah sistem yang dibangun sudah sesuai dengan kebutuhan fungsional atau belum. Susuai dengan kebutuhan fungsional yaitu memperoleh perbedaan yang signifikan dari sistem manual (sistem lama) dengan sistem yang baru. Berikut merupakan perbandingan sistem lama dengan sistem baru dapat dilihat pada tabel 7 : 
Citec Journal, Vol. 1, No. 4, Agustus 2014 - Oktober 2014

Tabel 7. Perbandingan pengujian sistem

\begin{tabular}{|c|c|c|c|c|c|}
\hline \multirow{2}{*}{ no } & \multirow{2}{*}{ NAMA KRT } & \multicolumn{2}{|c|}{ ALAMAT } & \multirow{2}{*}{ Sistem lama } & \multirow{2}{*}{ Rekomend asi sistem } \\
\hline & & RT & RW & & \\
\hline 1 & RISWAN & 1 & 4 & Lasyak & Tidal Layal \\
\hline 2 & TARYANA & 1 & 4 & Layalk & Layalk \\
\hline 3 & TARJA & 1 & 4 & Layalk & Layak \\
\hline 4 & MUNASEH & 1 & 4 & Layal: & Layak \\
\hline 5 & DATENG & 1 & 4 & Layal: & Layyal: \\
\hline 6 & KARTONO & 1 & 4 & Layal: & Tidal Layalk \\
\hline 7 & SARI & 1 & 4 & Layalk & Layalk \\
\hline 8 & IIYAS & 1 & 4 & Layal: & Layak \\
\hline 9 & ENDANG SUKENDA & 1 & 4 & Lasyal: & Tidak: Layalk \\
\hline 10 & EKO HARDIANSYAH & 1 & 4 & Layalk & Layak \\
\hline 11 & SITI & 1 & 4 & Layalk & Layak: \\
\hline 12 & SOPYAN & 1 & 4 & Layalk & Layal: \\
\hline 13 & RATTM & 1 & 4 & Layalk & Layal: \\
\hline 14 & CASWA & 1 & 4 & Layal: & Layalk \\
\hline 15 & ARWADI & 1 & 4 & Layalk & Layal: \\
\hline 16 & WARID & 2 & 4 & Lasyal: & Layal: \\
\hline 17 & DATAM & 2 & 4 & Layal: & Layal: \\
\hline 18 & KADIM & 2 & 4 & Layalk & Tidak: Layalk \\
\hline 19 & RASBUN & 2 & 4 & Layal: & Tidak: Layalk \\
\hline 20 & DIRLAM & 2 & 4 & Lasyak & Tidak Layalk \\
\hline 21 & WARTONO & 2 & 4 & Layalk & Layalk \\
\hline 22 & WARYADI & 2 & 4 & Layal: & Layalk \\
\hline 23 & DAURI & 2 & 4 & Lasyak & Tidal: Layalk \\
\hline 24 & MAARDI & 2 & 4 & Layal: & Layal: \\
\hline 25 & KARSIM & 2 & 4 & Layalk & Tidal: Layalk \\
\hline 26 & KASMADI & 2 & 4 & Layal: & Layal: \\
\hline 27 & ROHATI & 2 & 4 & Layal: & Layal: \\
\hline 28 & ROKENAH & 2 & 4 & Layalk & Layal: \\
\hline 29 & KARIMAH & 2 & 4 & Layal: & Layal: \\
\hline 30 & USMAN & 2 & 4 & Layal: & Layalk \\
\hline 31 & RASKANI & 2 & 4 & Layal: & Tidak: Layalk \\
\hline 32 & KASAM & 2 & 4 & Layalk & Tidak Layalk \\
\hline 33 & SUBADA & 2 & 4 & Laysal: & Layak \\
\hline 34 & KARSITA & 3 & 4 & Layal: & Tidal; Layalk \\
\hline 35 & SAMAD & 3 & 4 & Layyal: & Layalk \\
\hline 36 & KASNO & 3 & 4 & Layalk & Tidak Layalk \\
\hline 37 & KATTYEM & 3 & 4 & Layalk & Layalk \\
\hline 38 & ISMAII & 3 & 4 & Layal: & Tidak Layalk \\
\hline 39 & SADIRNN & 3 & 4 & Layalk & Tidak: Layalk \\
\hline 40 & KASINGKEM & 3 & 4 & Lasyak & Layak \\
\hline
\end{tabular}

Berdasarkan tabel perbandingan sistem lama dengan sistem baru dapat dilihat bahwa masih banyak data yang menunjukan masyarakat yang seharusnya tidak layak menerima dana BLSM masih mendapatkan dana BLSM. Pada sistem lama di Desa Mundakjaya tercatat 40 sampel KK yang mendapatkan BLSM artinya 100\%, setelah dilakukan perhitungan menggunakan sistem baru sebanyak $14 \mathrm{KK}$ atau 35\% yang sebenarnya tidak layak mendapatkan BLSM dan 65\% yang dinyatakan layak mendapatkan BLSM.

Berdasarkan hasil uji tersebut, sistem pendukung keputusan yang dirancang dapat menyeleksi kelayakan penerima BLSM. 


\subsection{Analisis Hasil}

\subsubsection{Desain Tampilan Sistem}

Halaman login berfungsi untuk memasukkan data pengguna yang ingin menggunakan sistem. Jika data tersebut benar, maka pengguna akan masuk ke dalam sistem, namun jika data tersebut salah, maka sistem akan memberi peringatan. Berikut tampilan form menu log-in sistem ini.

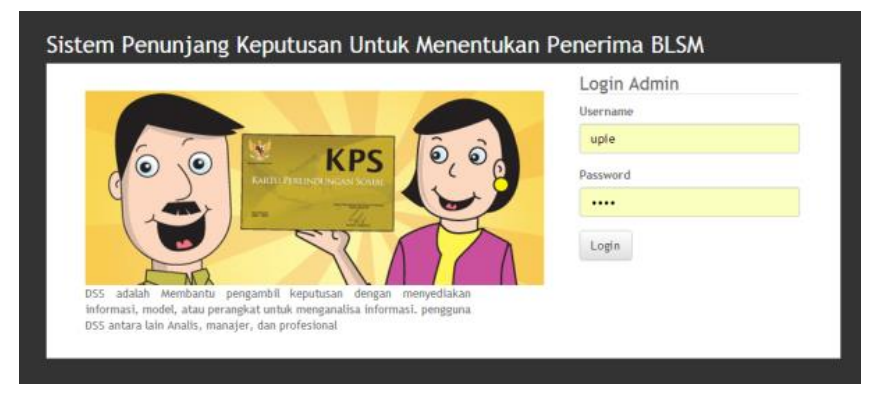

Gambar 4. Login

Menu utama merupakan tampilan keseluruhan sistem yang berisi menu-menu yang dapat dipakai untuk menggunakan sistem. Dapat dilihat pada gambar 5.

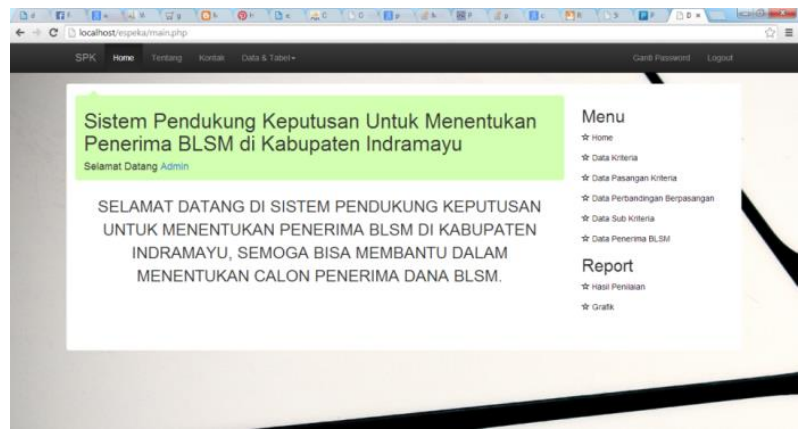

Gambar 5. Menu Utama

Tampilan grafik adalah alat bantu untuk pengguna jika ingin melihat hasil akhir dalam bentuk diagram sehingga memudahkan pengguna untuk membandingkan nilai antar penerima. Berikut tampilan menu penentuan nilai keputusan pada sistem ini dapat dilihat pada gambar 5 .

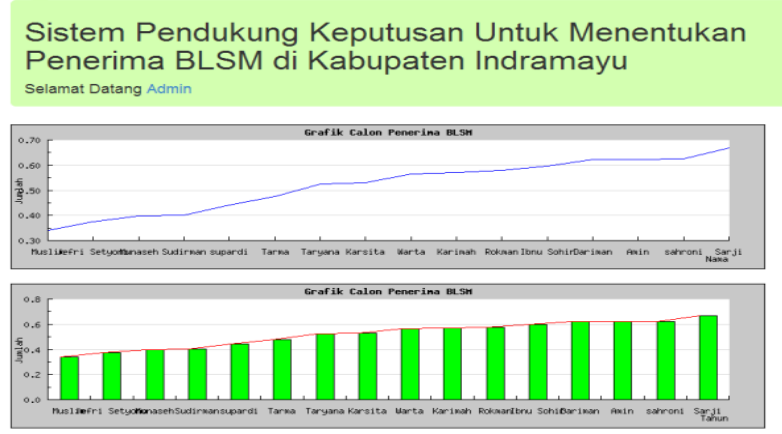

Gambar 6. Tampilan Grafik 


\section{KESIMPULAN}

Dari hasil pengujian sistem yang telah dilakukan, maka dapat diambil beberapa kesimpulan daiantaranya sebagai berikut:

1. Sistem Pendukung keputusan untuk menentukan penerima BLSM di Kabupaten Indramayu ini dapat membantu pihak pemerintah daerah dalam menentukan penerima BLSM dengan mengambil nilai hasil akhir penerima yang tertinggi.

2. Berdasarkan pengujian sistem yang dilakukan, perbedaan penggunaan sistem pendukung keputusan penerima BLSM dapat menyaring 35\% penerima atau sebanyak 14 KK dari 40 sampel KK yang seharusnya tidak layak menerima bantuan.

3. Sistem ini hanya menjadi alat bantu bagi pengambil keputusan, keputusan akhir tetap berada di tangan pengambil keputusan.

\section{SARAN}

Saran yang dapat diajukan untuk pengembangan dan perbaikan Sistem Pendukung Keputusan untuk menentukan penerimaan BLSM adalah untuk penelitian selanjutnya dapat dilengkapi dengan Sistem Informasi Geografis (SIG) untuk mengetahui pola sehingga dapat dipetakan wilayah penduduk yang layak atau tidak layak menerima BLSM.

\section{DAFTAR PUSTAKA}

[1] Tim Sosialisasi penyesuaian Subsidi Bahan Bakar Minyak, 2013, Solusi Masalah Kepesertaan \& Pemutakhiran Data Penerima Kartu Perlindungan Sosial (KPS), Jakarta.

[2] Hermawan, I., 2013, Bantuan Langsung Sementara Masyarakat, http://berkas.dpr.go.id/pengkajian/files/info_singkat/Info\%20Singkat-V-13-I-P3DI-Juli2013-79.pdf., diakses tanggal 2 Oktober 2013.

[3] TNP2K, 2013, Panduan TKSK Program Percepatan Perluasan Perlindungan Sosial (P4S) dan Bantuan Langsung Sementara Masyarakat (BLSM) tahun 2013, Jakarta.

[4] Istara, A. W., Cahyani, A. D., Rachman, F. H., 2013, Sistem Pendukung Keputusan Penentuan Pemberian Bantuan Raskin Menggunakan Metode Smarter, Jurnal Sarjana Teknik Informatika, vol 1, no 1, hal 1-8.

[5] Kusrini, 2007, Konsep dan Aplikasi Sistem Pendukung Keputusan. Penerbit Andi, Yogyakarta.

[6] Kusumadewi, S., Hartati, S., Harjoko, A., Wardoyo, R. 2006, Fuzzy Multi-Atribute Decision Making (FUZZY MADM), Penerbit Graha Ilmu, Yogyakarta.

[7] Idris, S. A. L., 2012, Analisis Perbandingan Metode Analytical Hierarchy Process (AHP) dan Simple Additive Weighting (SAW), Skripsi, Program Studi Sistem Informasi, Fakultas Teknik Universitas Negeri Gorontalo.

[8] Baskerville, R. L., 1999, Investigating Information System with Action Research, Communications of the Association for Information Systems (CAIS), vol 2, no 3.

[9] Tim Media Edukasi, 2012, Desain PTK Model Kurt Lewin, http://www.medukasi.web.id/2012/05/desain-ptk-model-kurt-lewin.html, diakses tanggal 01 Desember 2013

[10] Hasibuan, M. S. P., 2007, Manajemen Sumber Daya Manusia, Bumi Aksara, Jakarta. 